\title{
OPTIMIZATION OF FLASK CULTURE MEDIUM AND CONDITIONS FOR HYALURONIC ACID PRODUCTION BY A STREPTOCOCCUS EQUISIMILIS MUTANT NC2168
}

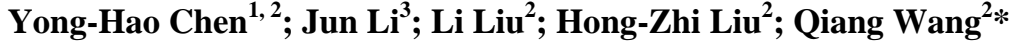 \\ ${ }^{1}$ Institute of Forestry and Pomology, Beijing Academy of Agriculture and Forestry Sciences, Beijing 100093, China; ${ }^{2}$ Institute \\ of Agro-food Science and Technology, Chinese Academy of Agricultural Sciences, Beijing 100193, China; ${ }^{3}$ Beijing Institute of \\ landscape architecture, Beijing 100102, China.
}

Submitted: August 04, 2011; Approved: June 07, 2012.

\begin{abstract}
A mutant designated NC2168, which was selected from wild-type Streptococcus equisimilis CVCC55116 by ultraviolet ray combined with ${ }^{60} \mathrm{C}_{0}-\gamma$ ray treatment and does not produce streptolysin, was employed to produce hyaluronic acid (HA). In order to increase the output of HA in a flask, the culture medium and conditions for NC2168 were optimized in this study. The influence of culture medium ingredients including carbon sources, nitrogen sources and metal ions on HA production was evaluated using factional factorial design. The mathematical model, which represented the effect of each medium component and their interaction on the yield of HA, was established by the quadratic rotary combination design and response surface method. The model estimated that, a maximal yield of HA could be obtained when the concentrations of yeast extract, peptone, glucose, and $\mathrm{MgSO}_{4}$ were set at $3 \mathrm{~g} / 100 \mathrm{~mL}, 2 \mathrm{~g} / 100 \mathrm{~mL}, 0.5 \mathrm{~g} / 100$ $\mathrm{mL}$ and $0.15 \mathrm{~g} / 100 \mathrm{~mL}$, respectively. Compared with the values obtained by other runs in the experimental design, the optimized medium resulted in a remarkable increase in the output of HA and the maximum of the predicted HA production was $174.76 \mathrm{mg} / \mathrm{L}$. The model developed was accurate and reliable for predicting the production of HA by NC2168.Cultivation conditions were optimized by an orthogonal experimental design and the optimal conditions were as follows: temperature $33^{\circ} \mathrm{C}, \mathrm{pH} 7.8$, agitation speed $200 \mathrm{rpm}$, medium volume $20 \mathrm{~mL}$.
\end{abstract}

Key words: Streptococcus equisimilis mutant; hyaluronic acid; optimization; culture medium; culture conditions

\section{INTRODUCTION}

Hyaluronic acid (HA), a linear, unbranched polysaccharide consisted of alternating N-acetyl-D-glucosamine and Dglucuronic acid, exists in many mammalian connective tissues such as joints, vitreous bodies, umbilical cords, cartilages, skins, and combs of fowls as a constituent; it plays an important role in many biological processes such as in tissue hydration, proteoglycan organisation in the extracellular matrix, and tissue repair (14). HA is a valuable biopolymer in

*Corresponding Author. Mailing address: Institute of Agro-food Science and Technology, Chinese Academy of Agricultural Sciences, Yuanmingyuan West Road 2 \#, Beijing, P. R. China, 100193.; Tel/Fax: 86-010-62818455.; E-mail: caaswangqiang@hotmail.com 
ophthalmics, orthopaedics, wound healing, tissue engineering, drug delivery, cosmetics, and as a vaccine aid $(2,6,15)$.

In recent years, instead of extracting HA from rooster combs and umbilical cord, preparing HA through microbial fermentation is being used more, because the risk of crossspecies viral infection can be avoided and the isolation process of high purity and high molecular weight $\mathrm{HA}$ can be simplified(5). This polymer is produced commercially by fermentation of the Lance field group C streptococci, Streptococcus equi subspecies equsimilis and Streptococcus equi subspecies zooepidemicus which can produce a capsule that is composed of hyaluronic acid polymers identical to that found in mammalian connective tissues (10). However, Streptococcus spp. strain can produce streptolysin which causes hemolysis. Thus, it is very important that streptolysin is absent in the hyaluronic acid obtained by cultivation of the microorganism. According to the reports $(8,10,12)$, NTG treatment was an effective induced measure to obtain a mutant which does not produce streptolysin. However, in this study, a mutant designated NC2168, which was selected from wild-type Streptococcus equisimilis CVCC55116 by ultraviolet ray combined with ${ }^{60} \mathrm{C}_{0}-\gamma$ ray treatment and does not produce streptolysin, was employed to produce HA.

Because no general medium works best for a new strain being tested, the optimization of the medium for the new mutant is necessary (9). Meanwhile, large numbers of experiments in stirred controlled vessels are not practical. However, the best medium chosen from shake flask data can build a foundation for the large scale stirred tank, thus it's essential to improve the HA production through the optimization of shake flask medium and cultivation conditions.

As a collection of statistical techniques for experiment designing, model developing and factors evaluating, response surface methodology (RSM) has been extensively applied in optimization of medium composition, conditions of enzymatic hydrolysis, fermentation and food manufacturing processes (3, $11,13,17$,$) . In this study, to increase the yield of HA, the$ optimum medium composition was carried out by RSM and the optimum cultivation conditions including temperature, rotate speed, $\mathrm{pH}$, and medium volume were investigated through orthogonal experimental design.

\section{MATERIALS AND METHODS}

\section{Microorganism and Medium}

The strain used in this study was Streptococcus equisimilis CVCC55116, from Chinese Veterinary Culture Collection. Microorganisms were grown in a solid culture medium consisting of $1 \mathrm{~g}$ glucose, $16 \mathrm{~g}$ ox-brain extract powder, $4 \mathrm{~g}$ oxheart extract powder (Brain Heart Infusion, BHI), $10 \mathrm{~g}$ yeast extract and $20 \mathrm{~g}$ agar. The blood agar (Joint Logistics Department, Beijing Military Area Command) was used for the isolation of the mutant without hemolysin. The selected mutant was cultivated in the fermentation medium consisting of $20 \mathrm{~g}$ glucose, $16 \mathrm{~g}$ ox-brain extract powder, $4 \mathrm{~g}$ ox-heart extract powder (BHI), $10 \mathrm{~g}$ peptone, $2 \mathrm{~g} \mathrm{MgSO}_{4}$ and $2 \mathrm{~g} \mathrm{~K}_{2} \mathrm{HPO}_{4}$ per liter of distilled water. The cultivation conditions were: temperature $37^{\circ} \mathrm{C}, \mathrm{pH} 7.4$, and agitation speed $180 \mathrm{rpm}$.

\section{Mutagenesis}

Streptococcus equisimilis CVCC55116 was incubated at $37^{\circ} \mathrm{C}$ for $24 \mathrm{~h}$ on the agar plate. A single colony was inoculated in a $250 \mathrm{~mL}$ flask containing $50 \mathrm{~mL}$ of fermentation medium; it was incubated at $37^{\circ} \mathrm{C}$ for $12 \mathrm{~h}$. The grown cells were collected by centrifugation at $3,000 \mathrm{~g}$ for $20 \mathrm{~min}$ and washed with distilled water. The collected cells were resuspended in distilled water and performed ultraviolet ray mutagenesis in a dark room. After ultraviolet ray treatment, the cells were incubated at $37^{\circ} \mathrm{C}$ for $12 \mathrm{~h}$ in the fermentation medium and plated on the blood agar plate for the selection of nonhemolytic mutants. The mutant treated by ultraviolet ray was irradiated by ${ }^{60} \mathrm{C}_{\mathrm{O}}-\gamma$ ray with dose rate of $31.42 \mathrm{~Gy} / \mathrm{min}$. The irradiation doses of the two mutagenesis methods were based on irradiation time and corresponding the fatality rate. Through repeated screening, a high-producing hyaluronic acid mutant designated NC2168 was obtained. 


\section{Analytical Methods}

CTAB Turbidimetric method was applied to determine the HA content (1). Ultraviolet and visible spectrophotometer (Rili, China) was used here.

\section{Experiment design}

Based on the single factor experiments, the carbon and nitrogen source and inorganic salt were determined, and the response surface methodology (RSM) was employed to optimize the medium for the mutant NC2168.Then, 23 runs were carried out using a factorial central composite design to study four independent variables each at five levels. The four independent variables $\mathrm{X}_{1}$ (yeast extract), $\mathrm{X}_{2}$ (peptone), $\mathrm{X}_{3}$ (sucrose), and $\mathrm{X}_{4}\left(\mathrm{MgSO}_{4}\right)$ at five levels and the experimental design were given in Table 1. A mathematical model, describing the relationships between the process indices (the output of HA) and the medium component contents in a quadratic equation, was developed. The accuracy and general ability of the above polynomial model could be evaluated by the coefficient of determination $\mathrm{R}^{2}$. As for the optimization of the culture conditions, the experiment was arranged based on the 3 levels of orthogonal experimental design with 4 factors and 9 runs as shown in Table 3. Four independent variables representing temperature, rotate speed, initial $\mathrm{pH}$ and medium volume were employed respectively. In each case, the output of HA was monitored and all the experiments were carried out in triplicate for the average calculation.

\section{Statistical analysis}

Statistical evaluations were performed using F-test. A value of $p<0.05$ was considered significant. The quadratic model was obtained by a standard multinomial regression method for four factors using the software Statistica, version 6.0. The extremum was also acquired by differential coefficient calculation and canonical analysis which was used to predict the shape of the curve generated by the model. Variance analysis on the orthogonal experiment results was performed by SAS, version 8.0 .

\section{RESULTS AND DISCUSSION}

\section{Optimization of culture medium}

Effect of nitrogen sources on the output of HA: The

effect of organic and inorganic nitrogen sources on the yield of HA is shown in Figure 1a. It indicates that the output of HA based on inorganic source $\left(\mathrm{NH}_{4}\right)_{2} \mathrm{SO}_{4}$ was the lowest while those based on most of organic nitrogen sources were superior. The main reason might be that organic sources were more easily taken up, transported and absorbed while inorganic nitrogen could restrain the metabolism of the strain to some extent. It is easy to see that BHI was the best organic nitrogen source to cultivate the mutant NC2168 and the highest output of HA based on BHI touched $169.20 \mathrm{mg} / \mathrm{L}$, even with the medium containing $1 \mathrm{~g} / 100 \mathrm{~mL} \mathrm{BHI}$, the output was higher than that based on other nitrogen sources. However, the cost of $\mathrm{BHI}$ is several times higher than that of other nitrogen sources so that it is essential to find out a substitute to BHI. A composite medium containing multiple growth factors might meet the higher demand of Streptococcus on nutrition. As shown in Figure 1a, when the concentrations of yeast extract and peptone were $3 \mathrm{~g} / 100 \mathrm{~mL}$ and $2 \mathrm{~g} / 100 \mathrm{~mL}$, the output of HA got $114.25 \mathrm{mg} / \mathrm{L}$ and $101.23 \mathrm{mg} / \mathrm{L}$, respectively, which were the two better nitrogen sources besides BHI. The composite nitrogen source consisting of yeast extract and peptone might be a promising nitrogen source which could provide more necessary growth factors.

Based on the previous experiments, $3 \mathrm{~g} / 100 \mathrm{~mL}$ yeast extract and $2 \mathrm{~g} / 100 \mathrm{~mL}$ peptone were fixed respectively, and added $0.5,1.0,1.5,2.0$ and $2.5 \mathrm{~g} / 100 \mathrm{~mL}$ peptone and yeast extract into the medium to constitute the composite nitrogen sources. The results in Figure 1b shows that $141.64 \mathrm{mg} / \mathrm{L}$ yield of HA was obtained using $3 \mathrm{~g} / 100 \mathrm{~mL}$ yeast extract and 1.5 $\mathrm{g} / 100 \mathrm{~mL}$ peptone, which was increased by $23.97 \%$ compared with $114.25 \mathrm{mg} / \mathrm{L}$, using yeast extract only. 

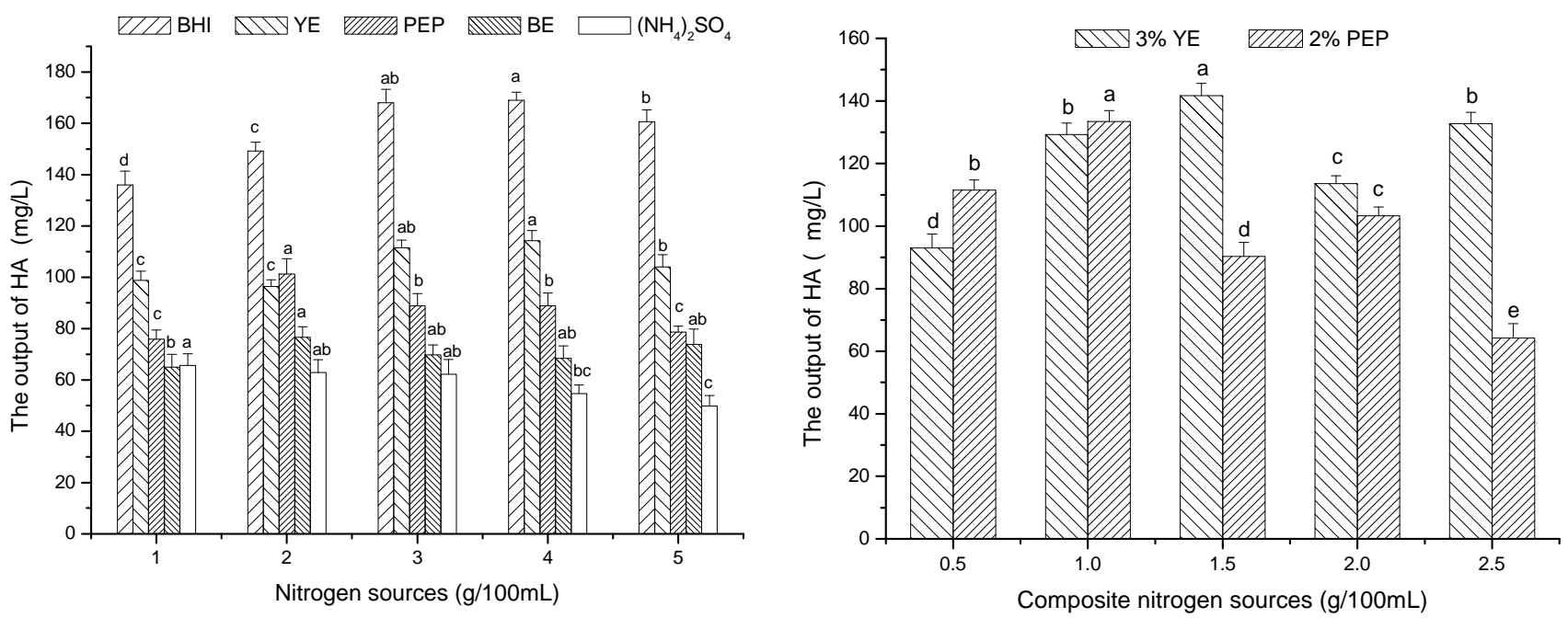

Figure 1. Effect of nitrogen sources on the output of HA "BHI" brain heart infusion, "YE" yeast extract, "PEP" peptone, "BE" beef extract. The "a-e," in Figure1-3 represented the significantly difference $(p<0.05)$ between the different concentration of the same medium component.

Effect of carbon sources on the output of HA: In this study, glucose, fructose, galactose, sucrose, maltose, xylose were used as the carbon sources respectively to enhance the yield of HA. Their influences at different concentrations are presented in Figure 2. It shows that the output of HA could be affected greatly by the kind and quantity of carbon sources. As shown in Figure 2, the highest output of HA was based on 0.5 $\mathrm{g} / 100 \mathrm{~mL}$ glucose as the carbon source. Other carbon sources including maltose at $1.5 \mathrm{~g} / 100 \mathrm{~mL}$, fructose at $0.5 \mathrm{~g} / 100 \mathrm{~mL}$ and sucrose at $0.5 \mathrm{~g} / 100 \mathrm{~mL}$ could obtain a higher output of HA. However, the galactose and xylose could not be utilized well and the corresponding output of HA was relatively low. We speculate that both UDP glucuronic acid and N-acetamide uridine diphosphoglucose are the synthesize precursors of HA and thalli. Maltose and sucrose could be easily decompounded into glucose by the thalli and fructose could be easily transformed into glucose so that they could be utilized better.

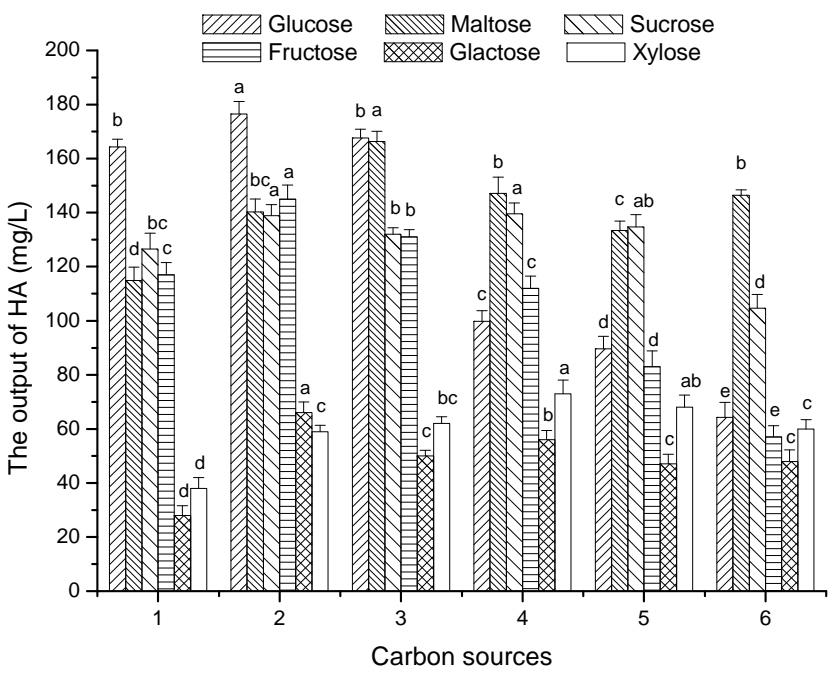

Figure 2. Effect of carbon sources on the output of HA. The numbers listed in the $\mathrm{X}$ axis represented 0.1, 0.5, 1.0, 2.0, 3.0, 4.0 $\mathrm{g} / 100 \mathrm{~mL}$ carbon sources respectively. 
Effect of metal ions on the output of HA: As for a cell, many metal ions are indispensable for active centers of an enzyme. During the process synthesizing HA, the HA synthetase is a key enzyme, which catalyzes the precursor of HA to synthesize HA (16). In this study, the effects of $\mathrm{Mg}^{2+}$ and $\mathrm{K}^{1+}$ on the output of HA were explored considering their possible roles in the HA synthetase. As shown in Figure 3, the highest output of HA was achieved up to $198.86 \mathrm{mg} / \mathrm{L}$ at $\mathrm{MgSO}_{4}$ concentration of $0.15 \mathrm{~g} / 100$ $\mathrm{mL}$ and the difference of output based on the different concentration of $\mathrm{MgSO}_{4}$ was pronounced $(p<0.05)$. However, as for $\mathrm{KH}_{2} \mathrm{PO}_{4}$, the output of $\mathrm{HA}$ based on the different concentration was almost the same, thus the effect of $\mathrm{KH}_{2} \mathrm{PO}_{4}$ concentration was negligible in the assigned range while $\mathrm{Mg}^{2+}$ was selected to be performed in the following experiment.

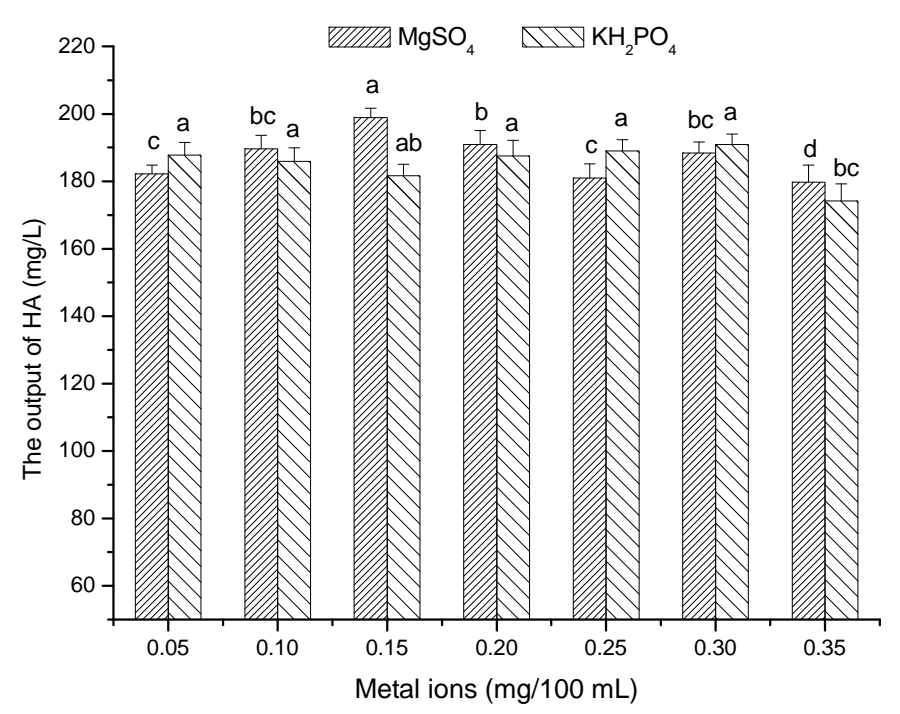

Figure 3. Effect of metal ions on the output of HA

\section{Orthogonal rotatable central composite design}

In the previous experiments, the suitability of various nitrogen sources, carbon sources, and metallic ions for the superior production of HA was evaluated. After the influence factors were determined, response surface method was used to optimize the culture medium for enhancing the output of HA through the quadratic rotary combination design $(4,7)$. A set of 23 experiments were required with four variables, and each variable being at five levels $(\alpha=1.682)$. The independent and dependent variables were analyzed to get regression equation, which was an empirical relationship between the HA output and the test variable in coded units. The regression equation obtained for the output of HA is as follows:

$$
\mathrm{Y}=174.76-3.39 \mathrm{X}_{1}+2.78 \mathrm{X}_{2}+6.09 \mathrm{X}_{3}+1.26 \mathrm{X}_{4}
$$

$$
-9.27 \mathrm{X}_{1}^{2}-12.93 \mathrm{X}_{2}^{2}-14.36 \mathrm{X}_{3}^{2}-12.21 \mathrm{X}_{4}^{2}
$$

$+1.03 \mathrm{X}_{1} \mathrm{X}_{2}-0.32 \mathrm{X}_{1} \mathrm{X}_{3}+0.91 \mathrm{X}_{1} \mathrm{X}_{4}+0.91 \mathrm{X}_{2} \mathrm{X}_{3}-0.32 \mathrm{X}_{2} \mathrm{X}_{4}-.03 \mathrm{X}_{3} \mathrm{X}_{4}$

$\mathrm{Y}$ represents the response, which is a dependent variable, the output of HA $(\mathrm{mg} / \mathrm{L})$, and $\mathrm{X}_{1}, \mathrm{X} 2, \mathrm{X}_{3}$, and $\mathrm{X}_{4}$ represent values of the independent variables, yeast extract, peptone, glucose and $\mathrm{MgSO}_{4}$, respectively.

Each of the observed value was compared with the predicted value which was calculated from the model, as depicted in Table 1. The statistical significance of the quadratic model equation was checked by analysis of variance (ANOVA), as shown in Table 2. The multiple coefficient of correlation $\mathrm{R}=0.9537$ indicates a close agreement between experimental and predicted value of the HA output. The total determination coefficient, $\mathrm{R}^{2}=0.9095$ implies that $90.95 \%$ of the variability in the response could be explained by the model. 
Table 1. Experimental design matrix of RSM and the responses of the dependent variables

\begin{tabular}{|c|c|c|c|c|c|c|}
\hline \multirow[b]{2}{*}{ Run } & \multicolumn{4}{|c|}{ Design matrix (g/100 mL) } & \multicolumn{2}{|c|}{ Output of HA( mg/L) } \\
\hline & Yeast extract & Peptone & Glucose & $\mathrm{MgSO}_{4} \cdot 7 \mathrm{H}_{2} \mathrm{O}$ & Experiment value & Fitted value \\
\hline 1 & $1(3.83)$ & $1(2.60)$ & $1(0.74)$ & $1(0.23)$ & 136.11 & 135.97 \\
\hline 2 & $1(3.83)$ & $-1(1.41)$ & $1(0.74)$ & $-1(0.07)$ & 124.39 & 120.13 \\
\hline 3 & $-1(2.17)$ & $1(2.60)$ & $1(0.74)$ & $-1(0.07)$ & 140.83 & 137.39 \\
\hline 4 & $-1(2.17)$ & $-1(1.41)$ & $1(0.74)$ & $1(0.23)$ & 136.6 & 134.83 \\
\hline 5 & $1(3.83)$ & $1(2.60)$ & $-1(0.26)$ & $-1(0.07)$ & 126.67 & 118.91 \\
\hline 6 & $1(3.83)$ & $-1(1.41)$ & $-1(0.26)$ & $1(0.23)$ & 121.46 & 115.39 \\
\hline 7 & $-1(2.17)$ & $1(2.60)$ & $-1(0.26)$ & $1(0.23)$ & 128.13 & 122.81 \\
\hline 8 & $-1(2.17)$ & $-1(1.41)$ & $-1(0.26)$ & $-1(0.07)$ & 131.88 & 122.49 \\
\hline 9 & $-1.68(1.60)$ & $0(2.00)$ & $0(0.50)$ & $0(0.15)$ & 111.53 & 123.90 \\
\hline 10 & $1.68(4.40)$ & $0(2.00)$ & $0(0.50)$ & $0(0.15)$ & 143.28 & 144.39 \\
\hline 11 & $0(3.00)$ & - & $0(0.50)$ & $0(0.15)$ & & \\
\hline & & $1.68(1.00)$ & & & 147.02 & 154.24 \\
\hline 12 & $0(3.00)$ & $1.68(3.00)$ & $0(0.50)$ & $0(0.15)$ & 136.6 & 142.84 \\
\hline 13 & $0(3.00)$ & $0(2.00)$ & - & $0(0.15)$ & & \\
\hline & & & $1.68(0.10)$ & & 125.36 & 133.51 \\
\hline 14 & $0(3.00)$ & $0(2.00)$ & $1.68(0.90)$ & $0(0.15)$ & 137.57 & 142.86 \\
\hline 15 & $0(3.00)$ & $0(2.00)$ & $0(0.50)$ & $-1.68(0.01)$ & 127.97 & 138.11 \\
\hline 16 & $0(3.00)$ & $0(2.00)$ & $0(0.50)$ & $1.68(0.29)$ & 139.04 & 142.34 \\
\hline 17 & $0(3.00)$ & $0(2.00)$ & $0(0.50)$ & $0(0.15)$ & 189.00 & 174.76 \\
\hline 18 & $0(3.00)$ & $0(2.00)$ & $0(0.50)$ & $0(0.15)$ & 183.16 & 174.76 \\
\hline 19 & $0(3.00)$ & $0(2.00)$ & $0(0.50)$ & $0(0.15)$ & 176.16 & 174.76 \\
\hline 20 & $0(3.00)$ & $0(2.00)$ & $0(0.50)$ & $0(0.15)$ & 172.25 & 174.76 \\
\hline 21 & $0(3.00)$ & $0(2.00)$ & $0(0.50)$ & $0(0.15)$ & 170.30 & 174.76 \\
\hline 22 & $0(3.00)$ & $0(2.00)$ & $0(0.50)$ & $0(0.15)$ & 170.62 & 174.76 \\
\hline 23 & $0(3.00)$ & $0(2.00)$ & $0(0.50)$ & $0(0.15)$ & 177.62 & 174.76 \\
\hline
\end{tabular}

The numbers in brackets were the actual values of the variables.

Table 2. Variance analysis for quadratic model and parameter estimates

\begin{tabular}{cccccc}
\hline Variables & SS & DF & MS & F & p-value \\
\hline $\mathrm{X}_{1}$ & 157.2006 & 1 & 157.2006 & 1.22456 & 0.30063 \\
$\mathrm{X}_{2}$ & 105.4269 & 1 & 105.4269 & 0.82125 & 0.39129 \\
$\mathrm{X}_{3}$ & 506.7100 & 1 & 506.7100 & 3.94716 & 0.08219 \\
$\mathrm{X}_{4}$ & 21.5302 & 1 & 21.5302 & 0.16772 & 0.69290 \\
$\mathrm{X}_{1} \mathrm{X}_{1}$ & 1286.6569 & 1 & 1286.6569 & 10.02277 & 0.01328 \\
$\mathrm{X}_{2} \mathrm{X}_{2}$ & 2555.3209 & 1 & 2555.3209 & 19.90538 & 0.00211 \\
$\mathrm{X}_{3} \mathrm{X}_{3}$ & 3170.9927 & 1 & 3170.9927 & 24.70132 & 0.00109 \\
$\mathrm{X}_{4} \mathrm{X}_{4}$ & 2271.0275 & 1 & 2271.0275 & 17.69079 & 0.00297 \\
$\mathrm{X}_{1} \mathrm{X}_{2}$ & 16.9127 & 1 & 16.9127 & 0.13175 & 0.72603 \\
$\mathrm{X}_{1} \mathrm{X}_{3}$ & 1.5939 & 1 & 1.5939 & 0.01242 & 0.91402 \\
$\mathrm{X}_{1} \mathrm{X}_{4}$ & 13.1225 & 1 & 13.1225 & 0.10222 & 0.75737 \\
$\mathrm{X}_{2} \mathrm{X}_{3}$ & 13.1225 & 1 & 13.1225 & 0.10222 & 0.75737 \\
$\mathrm{X}_{2} \mathrm{X}_{4}$ & 1.5939 & 1 & 1.5939 & 0.01242 & 0.91402 \\
$\mathrm{X}_{3} \mathrm{X}_{4}$ & 16.9127 & 1 & 16.9127 & 0.13175 & 0.72603 \\
$\mathrm{X}_{2} \mathrm{X}_{3}$ & 13.1225 & 1 & 13.1225 & 0.10222 & 0.75737 \\
Model & 10327.2038 & 14 & 737.6574 & $\mathrm{~F} 2=5.746$ & 0.00229 \\
Residual & 1026.9872 & 8 & 128.3734 & & \\
Lack of fit & 735.7965 & 2 & 367.8982 & $\mathrm{~F} 1=7.581$ & 0.01423 \\
Pure error & 291.1908 & 6 & 48.5318 & & \\
\hline
\end{tabular}

$\mathrm{R}=0.9537 ; \mathrm{R}^{2}=0.9095 ; \mathrm{R}^{2}(\mathrm{Adj})=0.8191 ; \mathrm{SS}$, sum of squares; $\mathrm{DF}$, degrees of freedom; MS, mean squares 
The significance of each coefficient was checked using the variance ratio test (F-test) and $p$ - value in Table 2 . On the one hand, the F-test result shows that $\mathrm{F}_{0.05}(2,6)=5.14<\mathrm{F}_{1}=$ $7.581<\mathrm{F}_{0.01}(2,6)=10.92$, which implies that the Lack of Fit was significant wherein $\alpha=0.05$ level but not significant wherein $\alpha=0.01$ level. Based on the analysis of the culture medium composition, it manifests that the existence of the Lack of Fit factors were mainly due to the high order interaction. On the other hand, $F_{2}=5.746>F_{0.01}(14,8)=5.56$ indicates that the regression equation was significant at $\alpha=0.01$ level.

The $p$-value less than 0.05 indicates that the model terms were significant. The corresponding variables will be more significant if the absolute F-value becomes larger and the $p$ value becomes smaller. In this case, it can be seen that the variables with the remarkable effects on the level of HA production were the quadratic term of glucose $\left(\mathrm{X}_{3} \mathrm{X}_{3}\right)$, peptone $\left(\mathrm{X}_{2} \mathrm{X}_{2}\right), \mathrm{MgSO}_{4}\left(\mathrm{X}_{4} \mathrm{X}_{4}\right)$, yeast extract $\left(\mathrm{X}_{1} \mathrm{X}_{1}\right)$. The $p$-value greater than 0.10 indicate that the model terms were not significant.

The maximum of the model was obtained from the equation when the concentration of yeast extract, peptone, glucose and $\mathrm{MgSO}_{4}$ were at $3.00 \mathrm{~g} / 100 \mathrm{~mL}, 2.00 \mathrm{~g} / 100 \mathrm{~mL}, 0.5$ $\mathrm{g} / 100 \mathrm{~mL}$ and $0.15 \mathrm{~g} / 100 \mathrm{~mL}$, respectively. The maximum of the predicted HA production was $174.76 \mathrm{mg} / \mathrm{L}$. The triplicate experiments were also carried out to verify the accuracy of the result for HA production in a similar way as that of production model. Under the calculated optimal culture condition, the mean value of HA production was $178.53 \pm 3.50 \mathrm{mg} / \mathrm{L}$, which was in agreement with the predicted value well. The average relative error between actual value and predicted value was $4.95 \%$. Therefore, the model developed was considered to be accurate and reliable for predicting the production of HA by NC2168.

The 3-D response surface and the 2-D contour plots were the graphical representations of the regression equation (13) and showed the effect of each independent variable and also their mutual effects on the production of HA. The response surface curves and also contour plots for variations in HA production were depicted in Figure 4. The response surface representing HA yield was a function of the concentrations of the two medium components with other ingredients being at an optimal level. By using the response surface plot, the interaction between two variables and their optimum levels can be easily understood and located. The HA output was influenced by all the four independent variables. The maximum point was achieved when glucose, peptone, yeast extract and $\mathrm{MgSO}_{4}$ concentrations were at their zero levels.
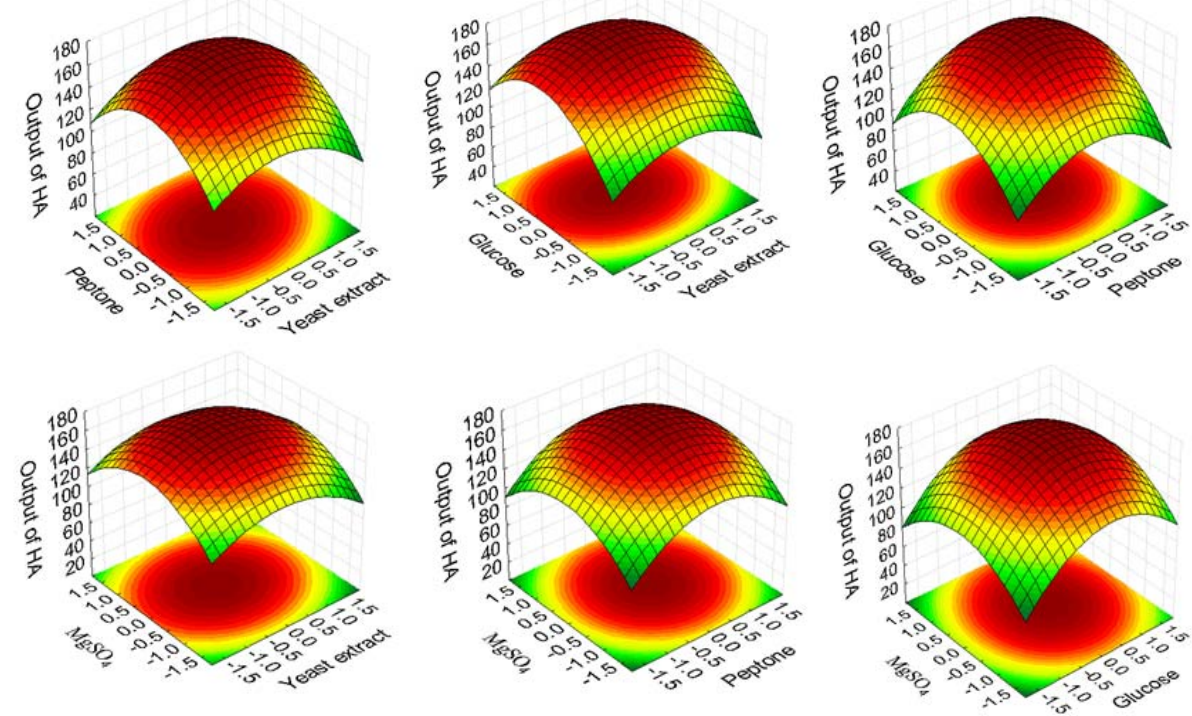

Figure 4. Response surface and contour plot of each independent variable effect and also their mutual effects on the production of HA 


\section{Optimization of culture condition}

The effect of four factors: temperature, rotate speed, original $\mathrm{pH}$ and medium volume on the output of HA under the orthogonal experimental design are presented in Table 3. The intuitionistic analysis shows that the maximum HA production was $196.73 \mathrm{mg} / \mathrm{L}$, which was got by the fifth run. The optimum culture condition was: initial $\mathrm{pH}=7.8$; medium volume $=20 \mathrm{~mL}$; temperature $=33^{\circ} \mathrm{C}$; rotate speed $=150 \mathrm{rpm}$. The range analysis manifests that the factors order for the effect was: initial $\mathrm{pH}>$ medium volume $>$ temperature $>$ rotate speed

The variance analysis (Table 4) showed that the effects of $\mathrm{pH}$ and medium volume were extremely significant $(p<0.01)$ and the effect of temperature was significant $(p<0.05)$. The result was in agreement with the range analysis. The validated experiment was run at the optimum condition mentioned above. HA output touched $224.52 \mathrm{mg} / \mathrm{L}$, which was also in agreement with the orthogonal experiment result.

Table 3. Orthogonal design and responsive value

\begin{tabular}{cccccc}
\hline Run & $\begin{array}{c}\text { Temperature } \\
\left({ }^{\circ} \mathbf{C}\right)\end{array}$ & $\begin{array}{c}\text { Rotate speed } \\
(\mathbf{r p m})\end{array}$ & pH value & $\begin{array}{c}\text { Medium volume } \\
(\mathbf{m l})\end{array}$ & $\begin{array}{c}\text { Output of HA } \\
(\mathbf{~ m g} / \mathbf{L})\end{array}$ \\
\hline 1 & $1(31)$ & $1(100)$ & $1(7.0)$ & $1(20)$ & 103.06 \\
2 & $1(31)$ & $2(150)$ & $2(7.4)$ & $2(30)$ & 109.91 \\
3 & $1(31)$ & $3(200)$ & $3(7.8)$ & $3(40)$ & 147.43 \\
4 & $2(33)$ & $1(100)$ & $2(7.4)$ & $3(40)$ & 128.40 \\
5 & $2(33)$ & $2(150)$ & $3(7.8)$ & $1(20)$ & 196.73 \\
6 & $2(33)$ & $3(200)$ & $1(7.0)$ & $2(30)$ & 96.90 \\
7 & $3(35)$ & $1(100)$ & $3(7.8)$ & $2(30)$ & 129.31 \\
8 & $3(35)$ & $2(150)$ & $1(7.0)$ & $3(40)$ & 75.21 \\
9 & $3(35)$ & $3(200)$ & $2(7.4)$ & $1(20)$ & 144.59 \\
$\mathrm{R}$ & 24.31 & 9.48 & 66.1 & 36.09 & \\
\hline
\end{tabular}

Table 4. Variance analysis on the orthogonal experiment results

\begin{tabular}{ccccc}
\hline Source & Degr. of $\boldsymbol{f}$ & $\mathbf{F}$ & $\boldsymbol{p}$-value & Significance \\
\hline block & 2 & 0.15 & 0.8653 & \\
Temperature & 2 & 5.72 & 0.0133 & $*$ \\
Rotate speed & 2 & 3.44 & 0.0571 & \\
pH & 2 & 75.81 & $<.0001$ & $* *$ \\
Medium volume & 2 & 18.68 & $<.0001$ & $* *$ \\
\hline
\end{tabular}

\section{CONCLUSION}

As to the new mutant Streptococcus equisimilis NC2168 without producing streptomycin, of which the optimum culture medium for maximum HA production was carried out with orthogonal rotatable central composite design and RSM. The model developed was considerably accurate and reliable for predicting the production of HA by NC2168 and a maximum of $174.76 \mathrm{mg} / \mathrm{L} \mathrm{HA}$ was obtained using the optimal culture medium as follows: yeast extract $=3 \mathrm{~g} / 100 \mathrm{~mL}$, peptone $=2$ $\mathrm{g} / 100 \mathrm{~mL}$, glucose $=0.5 \mathrm{~g} / 100 \mathrm{~mL}, \mathrm{MgSO}_{4}=0.15 \mathrm{~g} / 100 \mathrm{~mL}$. The optimized culture condition was: temperature $32^{\circ} \mathrm{C}$, rotate speed $200 \mathrm{rpm}$, initial pH 7.8, and medium volume $20 \mathrm{~mL}$. The maximum HA production was $224.52 \mathrm{mg} / \mathrm{L}$ under the optimum condition. It is evident that the output of HA was affected significantly by culture medium and conditions optimization. The NC2168 showed 149.08\% increase in HA production under the optimum culture medium and conditions. This design proved to be crucial in achieving increase in the production of HA.

\section{ACKNOWLEDGEMENTS}

This work was supported by Key Projects in the National 
Science and Technology Pillar Program (No.2010 BAD05A01-

09) and by the Foundation of Chinese Academy of Agricultural Sciences for Outstanding Researchers.

\section{REFERENCES}

1. Chen, Y. H.; Wang, Q. (2009). Establishment of CTAB Turbidimetric method to determine hyaluronic acid content in fermentation broth.Carbohyd. Polym. 78: 178-181.

2. Crescenzi, V. (1995). Microbial polysaccharides of applied interest: ongoing research activities in Europe. Biotechnol. Prog. 11: 251-259.

3. Cui, F. J.; Li, Y.; Xu, Z. H.; Xu, H. Y.; Sun, K.; Tao, W. Y. (2006). Optimization of the medium composition for production of mycelial biomass and exopolymer by Grifola frondosa GF9801 using response surface methodology. Bioresour. Technol. 97: 1209-1216.

4. Feng, Y. Y.; He, Z. M.; Ong, S. L.; Hu, J. Y.; Zhang, Z. G.; Ng, W. J. (2003). Optimization of agitation, aeration, and temperature conditions for maximum $\beta$-mannanase production. Enzyme. and Microbial. Techonol. 32: 282-289.

5. Fong Chong, B.; Blank, L. M.; Mclaughlin, R.; Nielsen, L. K. (2005) Microbial hyaluronic acid production. Appl. Microbiol. Biotechnol. 66: 341-351.

6. Fong Chong, B.; Nielsen, L. K. (2003). Amplifying the cellular reduction potential of Streptococcus zooepidemicus. J. Biotechnol. 100: 33-41.

7. Hanan, M. I.; Wan, M.; Wan, Y.; Aidil, A. H. (2005). Optimization of medium for the production of $\beta$-cyclodextrin glucanotransferase using Central Composite Design (CCD). Process. Biochem. 40: 753-758.

8. Hosoya, H.; Kimura, M.; Endo, H. (1994). Novel production process of hyaluronic acid and bacterium strain therefore as well as cosmetic composition containing hyaluronic acid. Eur. Pat. 0, 244, 757.

9. Kennedy, M.; Krouse, D. (1999). Strategies for improving fermentation medium performance: a review. J. Ind. Microbiol. Biotechnol. 23: 456475.

10. Kim, J. H.; Yoo,S. J.; Oh, d. k.; Kweon Y. G.; Park D. W.; Lee C. H., Gil G. H. (1996). Selection of a Streptococcus equi mutant and optimization of culture conditions for the production of high molecular weight hyaluronic acid. Enzyme. Microbial. Technol. 19: 440-445.

11. Mao, X. B.; Eksriwong, T.; Chauvatcharin, S.; Zhong, J. J. (2005). Optimization of carbon source and carbon/nitrogen ratio for cordycepin production by submerged cultivation of medicinal mushroom Cordyceps militaris. Process. Biochem. 40: 1667-1672.

12. Nimrod, A.; Greenman, B.; Kanner, D. (1988). High molecular weight sodium hyaluronate.U.S.A. Pat. 4, 784, 990.

13. Oh, B. R.; Seo, J. W.; Choi, M. H.; Kim, C. H. (2008). Optimization of Culture Conditions for 1,3-Propanediol Production from Crude Glycerol by Klebsiella pneumoniae Using Response Surface Methodology. Biotechnol. Bioprocess. Eng. 13: 666-670.

14. Phrem, P. (1983). Synthesis of hyaluronate in differentiated teratocxcinoma cells: Characterization of the synthase. Biochem. J. 211: 181-189.

15. Radaeva, I. F.; Kostina, G. A.; Zmievskii, A.V. (1997). Hyaluronic acid: biological role, structure, synthesis, isolation, purification, and applications. Appl. Biochem. Microbiol.33:111-115.

16. Stoolmiller, A. C.; Dorfman, A. (1969). The Biosynthesis of hyaluronic acid by Streptococcus. J. Biol. Chem. 244(2): 236-246.

17. Wang, Y. X.; Lu, Z. X. (2005). Optimization of processing parameters for the mycelial growth and extracellular polysaccharide production by Boletus spp. ACCC50328. Process. Biochem. 40: 1043-1051. 